

\title{
Chloride ingress in cracked concrete: a laser induced breakdown spectroscopy (LIBS) study
}

\author{
Branko Šavija $^{1 *}$, Erik Schlangen ${ }^{2}$, José Pacheco $^{3}$, Steven Millar ${ }^{4}$, Thorsten Eichler ${ }^{4}$ and \\ Gerd Wilsch ${ }^{4}$
}

\begin{abstract}
Cracks are always present in reinforced concrete structures. In the presented research, influence of mechanical cracks on chloride ingress is studied. A compact reinforced concrete specimen was designed, mimicking the cracking behaviour of beam elements. Cracks of different widths were induced by means of mechanical loading. These cracked specimens were then subjected to weekly cycles of wetting and drying with $\mathrm{NaCl}$ solution. After the exposure, the specimens were cut, and chloride distributions were determined using Laser Induced Breakdown Spectroscopy (LIBS), an innovative technique which enables simultaneous determination of different elements with high spatial resolution and minimal specimen preparation. By combining element distributions of different elements, it is possible to discriminate between coarse aggregate particles, and the mortar matrix. It was found that the wider the crack is, the higher the ingress of chloride ions. This was, however, different for two tested concrete mixes. Due to highly inhomogeneous chloride distribution around the cracks, use of fine-scale experimental techniques for chloride mapping is advised, based on the presented study.
\end{abstract}

\section{Introduction and research significance}

Cracking is inevitable in reinforced concrete structures. Although not a structural problem, it could potentially be a durability issue. In the past two decades numerous studies have been devoted to ingress of chloride and reinforcement corrosion in cracked concrete (for an overview, see Šavija and Schlangen (2012), Pacheco and Polder (2012), and Šavija (2014)). However, there is no consensus on the issue yet. This paper aims at broadening the knowledge regarding the impact of cracks on chloride ingress.

First, a cracking procedure and specimen geometry needs to be selected. In a review by Šavija and Schlangen (2012) advantages and disadvantages of different cracking procedures proposed in the literature have been discussed. It was concluded that the cracks in laboratory specimens should resemble those in structural elements (beams) if the results of a study are to be applicable in engineering practice. Therefore, specimen geometry and cracking procedure should be selected to achieve this goal.

Most studies have been performed on plain (unreinforced) concrete specimens. However, reinforced con-

${ }^{1}$ PhD Student, Microlab, Delft University of Technology the Netherlands.

*Corresponding author, E-mail: b.savija@tudelft.nl

${ }^{2}$ Professor, Microlab, Delft University of Technology, the Netherlands.

${ }^{3} \mathrm{PhD}$ Student, Microlab, Delft University of Technology the Netherlands.

${ }^{4}$ Researcher, BAM-Federal Institute for Material Research and Testing, Division 8.2, Berlin, Germany. crete has somewhat different cracking behaviour than plain concrete. As tension is applied in the reinforcing steel, microcracks form in the steel/concrete interface (Goto 1971). Also, debonding of the steel/concrete interface occurs, possibly creating a fast pathway for fluid penetration. This was proven in an investigation by Zhang et al. (2010), who studied water penetration in reinforced cracked specimens using neutron radiography. Rapid moisture penetration along the damaged steel/concrete interface was observed. Pease (2010) also suggested that damage created in the steel/concrete interface might be much more detrimental to chloride ingress and steel corrosion than cracking of the concrete cover itself. Similar findings were reported by François et al. (2011).

A convenient way of creating controlled cracks in compact concrete specimens is the wedge-splitting method. Wedge-splitting method has long been used in fracture mechanics of concrete. Brühwiler and Wittmann (1990) used the test to determine fracture mechanics parameters of concrete, such as the specific fracture energy and the fracture toughness. Similar setups have been used in some durability studies. Reinhardt et al. (1998) used it as a way of creating controlled cracks in specimens which were subsequently subjected to fluid penetration. The penetration front through the specimen was monitored visually. It was observed that the penetration in front of the crack tip is slower than in the undisturbed zone. This essentially means that a bending crack cannot be treated as free surface, when it comes to fluid ingress. Furthermore, they concluded that concrete with crack widths below $0.03 \mathrm{~mm}$ behaves like uncracked concrete. Yoon et al. (2007) used a similar setup to prepare cracked specimens to be subjected to Rapid 
Chloride Migration tests. In their investigation, a threshold crack width for chloride migration was found, and said to be dependent on the concrete composition, among other things. Pease et al. (2009) also used the method to create controlled cracks in their investigation. Cracked specimens were then subjected to water penetration. The penetration front was monitored using Xray absorption. The investigation showed that only a portion of the total crack length contributes as a free surface to water sorption, while the remaining part of the crack length inhibits sorption. These investigations emphasize the impact of crack width variations and shape on the ingress behaviour.

However, in the standard wedge-splitting setup, plain concrete specimens are used. In the current study, a modified wedge-splitting method is used. Reinforcement is placed in the specimens to mimic the cracking behaviour of reinforced concrete beams, which somewhat alters the mechanical behaviour of the specimens.

In order to determine chloride ion distribution around the cracks, a meso-scale measurement technique (i.e. with spatial resolution in the $\mathrm{mm}$ range) should be used. Some of the techniques used in the literature are electron probe micro analysis (EPMA) (Win et al. 2011), laser ablation inductively coupled plasma mass spectrometry (LA-ICP-MS) (Silva et al. 2013), and laser induced breakdown spectroscopy (LIBS) (Wilsch et al. 2005; Weritz et al. 2006). In the current study, a LIBS setup at the BAM Federal Institute for Materials Research and Testing in Berlin, Germany, was used to determine chloride distribution in cracked specimens, as explained further.

\section{Materials and methods}

\subsection{Materials}

Two concrete mixes with w/c ratio of 0.45 were used in this study: a mix prepared with CEMI 52.5 R cement (designated OPC, Ordinary Portland Cement, mix), and a mix prepared with CEMIII/B $42.5 \mathrm{~N}$ cement (designated slag mix). Mix proportions for both mixes are given in Table 1.

The mixing procedure was as follows: first, fine aggregate was mixed for one minute. Then, cement was added, and mixing was continued for one minute more. After that, water (with superplasticizer) was added and mixed for four minutes. The mixing was then stopped for one minute. Finally, coarse aggregate was added and mixed for three minutes. The total mixing time was about ten minutes. The specimens were then cast. The average concrete strength after 28 days was $55.4 \mathrm{MPa}$ for the OPC mix and 47.3 MPa for the slag mix. Slump

Table 1 Concrete mixes used in the study $\left(\mathrm{kg} / \mathrm{m}^{3}\right)$.

\begin{tabular}{|c|c|c|c|c|c|}
\hline Mix & Water & Cement & Sand & Gravel & $\begin{array}{c}\text { Superplasticizer } \\
\text { (\% cement) }\end{array}$ \\
\hline OPC & 166 & 366 & 842 & 1027 & 1.4 \\
\hline Slag & 157 & 350 & 1055 & 844 & 1.4 \\
\hline
\end{tabular}

was about $10 \mathrm{~cm}$ for OPC series, and $18 \mathrm{~cm}$ for slag series, while air void content was $3.1 \%$ for OPC and $2.5 \%$ for slag series.

\subsection{Specimen preparation, cracking, and expo- sure}

The wedge-splitting method has been used in fracture mechanics of concrete for many years (Brühwiler and Wittmann 1990). This method is commonly used in fracture mechanics to determine fracture properties of concrete and rock. A prismatic specimen is provided with a groove and a notch. The wedge is installed in the groove and loaded in compression in the vertical direction. Rollers turn the vertical load into two horizontal loads, which move away from each other and crack the starter notch (Fig. 1). Using LVDTs (Linear Variable Displacement Transducers), the COD (crack opening displacement) at the bottom of the notch (i.e. where the crack is expected to initiate, see Fig. 2) can be measured, and the width of the crack can be controlled. Cracks created in this manner are $\mathrm{V}$-shaped cracks, and can be considered comparable to bending cracks. These specimens are typically not reinforced.

As mentioned in the introduction, cracking behaviour of reinforced concrete is somewhat different from plain concrete. Cracks form parallel to the reinforcing steel, with microcracks around it (Goto 1971). This effect could possibly be more important for chloride ingress (Pease 2010) and reinforcement corrosion than traversing cracks only (Arya and Ofori-Darko 1996). In order to study this effect, two ribbed reinforcing bars were placed in the specimens (Fig. 2 right). This modification enables crack branching around the steel rebar, with cracks forming parallel to the steel, instead perpendicular to it.

For the specimen preparation, cubic moulds of $150 \times 150 \times 150 \mathrm{~mm}^{3}$ are used. Inside the mould, two reinforcing bars of $12 \mathrm{~mm}$ diameter and about $120 \mathrm{~mm}$ in length are placed (Fig. 2). Prior to casting the specimens, a PVC profile with a cross section of $40 \times 40 \mathrm{~mm}^{2}$ is mounted on the mould, in order to create a recess. This PVC profile is removed around 2 hours after cast-

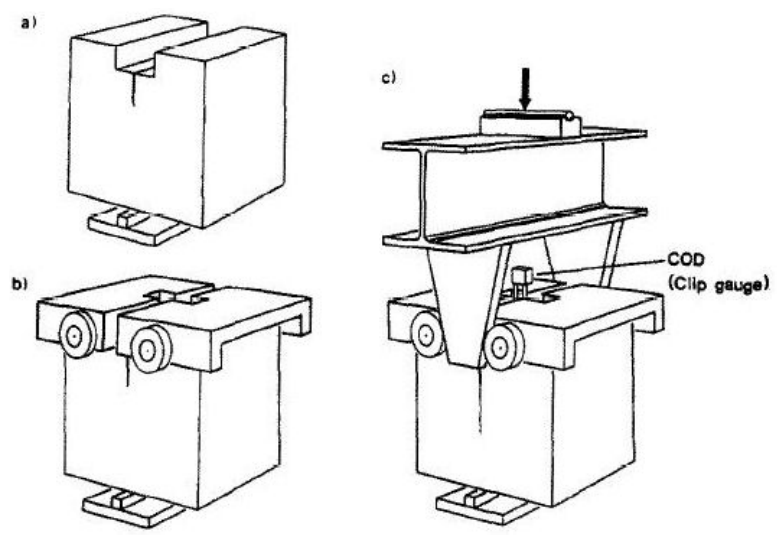

Fig. 1 The wedge splitting test for specimen cracking according to Brühwiler and Wittmann (1990). 


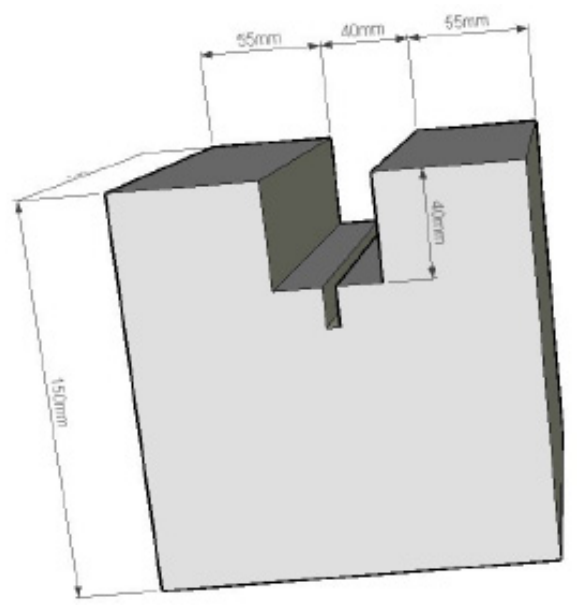

(a)

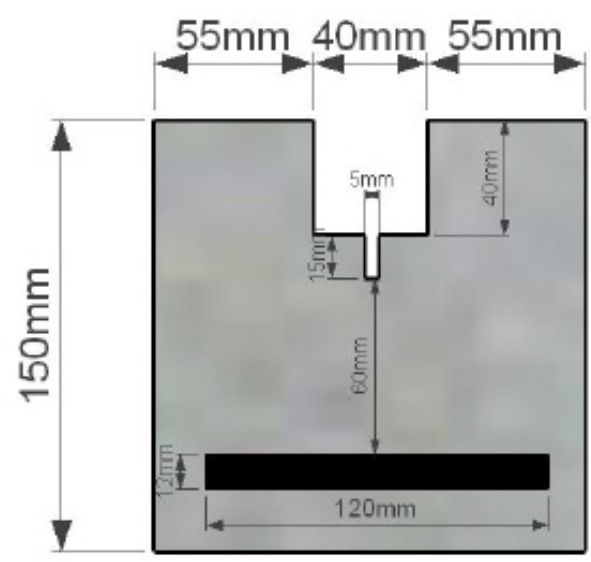

(b)

Fig. 2 Modified wedge splitting test (MWST) specimen geometry.

ing. This way, the desired specimen geometry is obtained. After the curing period, a notch ( $5 \mathrm{~mm}$ thick) is sawn in the specimen using a water cooled saw. The purpose of the notch is to guide the fracture process; namely, the crack should typically start from the notch. The depth of this notch can also be adjusted in order to achieve certain concrete cover depth. It should not be too shallow, however, since the crack then might initiate outside the notch.

Wedge-splitting specimens were taken out of the climate chamber after 28 days and thereafter stored at room temperature until testing. At the age of 36 days, cracking procedure was performed. In order to control the obtained crack width, LVDTs are placed on both sides of the specimen at the bottom of the notch, where the crack is expected to initiate. Their average is used as a feed-back signal for the machine, and controls the whole loading process. In this way, a stable cracking procedure is performed. The final (unloaded) crack width was recorded and this crack width was used in subsequent discussions. It has to be noted that these crack widths could reduce over time due to e.g. creep, however this was not measured.

After cracking, the specimens were stored in laboratory conditions for more than 7 days prior to exposure (hence, they were not water saturated). Then, they were exposed to weekly salt-dry cycles consisting of 48 hours of $3.3 \% \mathrm{NaCl}$ solution contained in the recess and 5 days of drying at $20{ }^{\circ} \mathrm{C}$ and $50 \% \mathrm{RH}$. The solution was poured in a pond formed by the recess and two rubber sheets glued to the sides of each specimen. The OPC series and the slag series were exposed to 45 and 36 weekly cycles, respectively. The exposure duration of slag series was shorter due to time constraints in the project. At the end of the exposure to chlorides, the OPC specimens were cut longitudinally (parallel to the reinforcement) into three pieces, and the middle piece was analysed using LIBS (Fig. 3a). For the slag series, the top part (i.e. the recess) was cut off first, to enable easier handling of the specimens. Then the specimens were cut

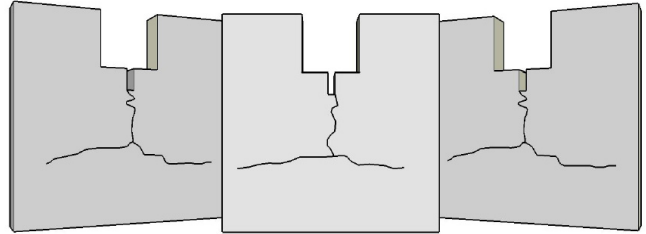

(a) OPC
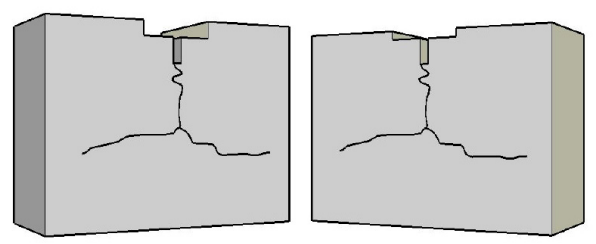

(b) Slag

Fig. 3 Cut specimens prior to LIBS analysis.

in half, shipped to Berlin, and one half was analysed using LIBS (Fig. 3b).

\subsection{Laser Induced Breakdown Spectroscopy (LIBS)}

Laser induced breakdown spectroscopy (LIBS) is a powerful and reliable optical technique for the detection of trace elements present in a solid, liquid or gaseous sample (Gondal et al. 2011). It is a sort of atomic emission spectroscopy where analyses are performed by monitoring intensities and wavelengths of the emission lines. A highly energetic laser pulse is focused to form a plasma on the surface of the specimen. The plasma excites and atomizes just a very small part of the specimen, and the atomic emission spectrum is recorded. In principle, all elements can be detected by LIBS, since all elements emit characteristic frequencies when excited to sufficiently high temperature. In practice, this is limited by the power of the laser, the focusing conditions, the sensitivity and the wavelength range of the detector and the spectrometer.

LIBS was used for determination of trace elements, 
such as chloride and sulphur, in cement based materials (Wilsch et al. 2005; Weritz et al. 2006; Gondal et al. 2011; Gehlen et al. 2009; Sugiyama et al. 2010). It can be considered as a meso-scale technique, with spatial resolution in $\mathrm{mm}$ range. Also, chloride ions are present only in the cement paste and not in the aggregate particles, and LIBS, with help of software tools, can discriminate between these locations based on other elements, such as $\mathrm{Ca}$, Si or $\mathrm{O}$.

\subsubsection{Experimental setup}

For the investigation, the experimental setup shown in Fig. 4 was used. A pulsed NdYAG laser (Big Sky) with an output energy of $400 \mathrm{~mJ}$ per pulse is used at a fundamental wavelength of $1064 \mathrm{~nm}$ at a frequency of 10 $\mathrm{Hz}$. The beam is expanded by a beam expander and focused on the sample surface with a lens (focal length $\mathrm{f}=$ $500 \mathrm{~mm}$ ). The spot size at the surface is $1.0 \mathrm{~mm}$. The light emitted from the plasma is guided by an optical fibre. The fibre is coupled to a Czerny-Turner type spectrometer (Shamrock 330i). In front of the entrance of the slit of the spectrometer an edge filter is located, and used to supress light with wavelength below $550 \mathrm{~nm}$. A CCD (Andor Idus DV420) is used as a detector.

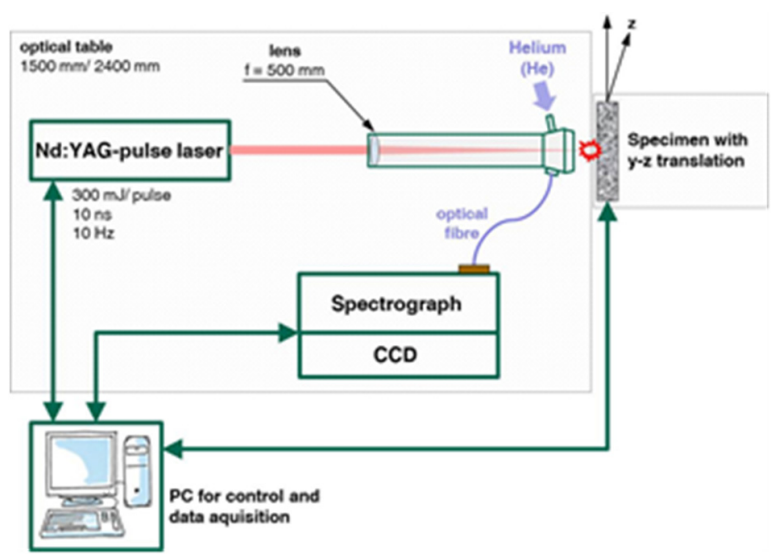

Fig. 4 Experimental set-up for LIBS at BAM Institute in Berlin.

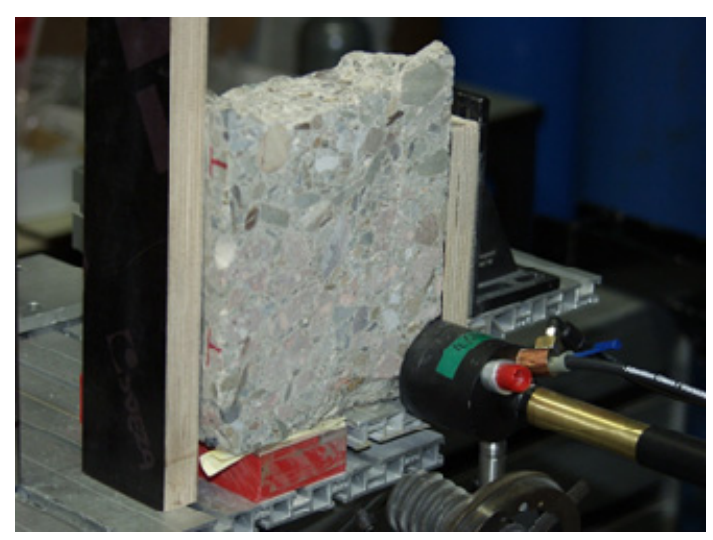

Fig. 5 Translation stage with one of the specimens. During the measurement, the specimen is moved line by line in the plane perpendicular to the laser beam.
The specimen under investigation is located on a translation stage and may be moved in plane perpendicular to the laser beam. To remove dust and to get a lower limit of detection, the environment of the plasma is purged with helium.

The setup is controlled by a Labview-based software. An automated measurement procedure minimizes the liability to errors and enables fast analysis of samples.

\subsubsection{Measurement}

For a measurement, the sample is placed on the translation stage at a constant distance to the lens (Fig. 5). The measurements are performed line by line. The distance between the lines is of the order of $0.25 \mathrm{~mm}$ to $1.0 \mathrm{~mm}$, depending on the resolution desired. The distance of subsequent measurements per line is also of the same order. In the current study, both distances were set to 1 $\mathrm{mm}$.

\subsubsection{Evaluation and Calibration}

Evaluation of LIBS data is performed by Labviewbased software which calculates, for every element under investigation and for every measurement point, the peak maximum in correlation to the background signal (Fig. 6).

The output is an element map over the measured area, which represents the colour coded intensity values per point. The software allows for differentiation between measurements performed on coarse aggregates and on the cement matrix by evaluation of calcium content for each point measured. Calibration is necessary to obtain quantitative results. This is done by measurements on a set of reference samples with known element content in a similar matrix. As an example, calibration curves for the evaluation of quantitative values of chlorine and sodium are shown in Figs. 7 and 8. It can be seen that the sensitivity for the evaluation of sodium is much higher compared to chlorine.

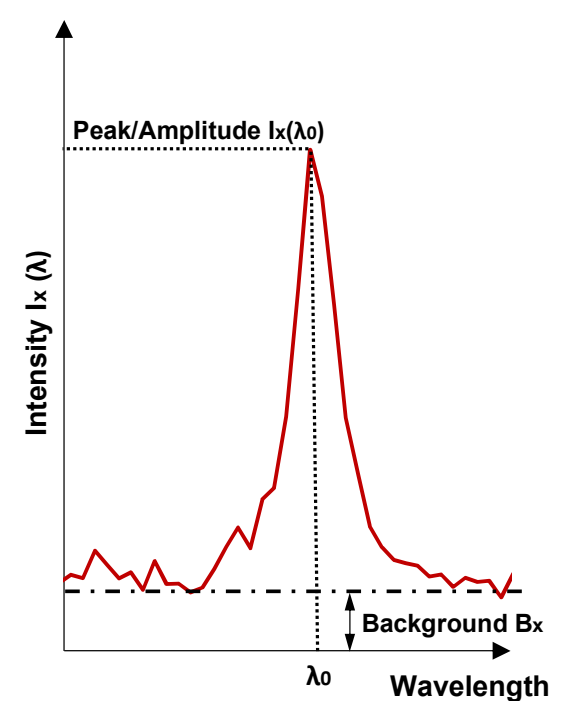

Fig. 6 Signal to Background Ratio for a certain wavelength. 


\subsubsection{Chloride detection}

The chlorine concentration in the cement or concrete can be determined by evaluation of the emission line $837.6 \mathrm{~nm}$ in the near infrared spectral range (Wilsch et al. 2005). Other chloride spectral lines are available in theory, but do not deliver the required sensitivity in practice. Alternatively, adequate results can be achieved only with the VUV (Vacuum UV) emission line at 137.7 $\mathrm{nm}$ under vacuum conditions. The chlorine line at 837.6 $\mathrm{nm}$ needs to be classified at outside the sensitivity range, unless the use of a gas purge with helium. Fig. 9 shows the effect of helium purge on the chlorine signal at $837.6 \mathrm{~nm}$.

\subsubsection{Benefits over other measurement tech- niques}

LIBS provides several advantages compared to wet chemical analyses:

- Multiple elements can be traced with a single LIBS measurement

- Element distributions can be obtained with millimetre resolution

- Imaging of element distributions is possible

- Due to relatively short duration of a measurement, more measurements of concrete specimens and whole structures can be performed within the same amount of time

- The method is, in principle, portable and can be used in harsh environments. Currently, a mobile LIBS setup for on-site element analysis is in testing phase (Wilsch et al. 2011)

Another major benefit of LIBS over both wet chemical analysis and microanalysis techniques such as EDS and EPMA, is the simple specimen preparation. A specimen can be split or cut, and the exposed concrete surface is then examined, and no grinding/crushing of concrete is needed. The large focal length $(500 \mathrm{~mm})$ is used in order to be able to investigate even rough surfaces (with roughness up to about $2 \mathrm{~mm}$ ).

LIBS has several major benefits over microanalysis techniques, such as EPMA (Electron Probe Microanalysis). EPMA is a powerful technique for quantifying the distributions of element concentrations at the surface on a wide range of materials (e.g. cement based materials by Mori et al. 2004). It has unquestionably a comparable high reproducibility of lower or equal $1 \%$. Even light elements starting with an atomic number of 4 can be detected.

Nevertheless, LIBS was the method of choice in the present case for several reasons. LIBS needs no vacuum conditions and no significant sample preparations were needed in order to determine the distribution of the element concentration in a comparable large surface area of about $100 \mathrm{~cm}^{2}$.

The present reproducibility of LIBS is adequate in the case of measuring highly heterogeneous concrete samples. Fig. 10 shows the variability of calibration curves for chloride measured at four different times within one month.

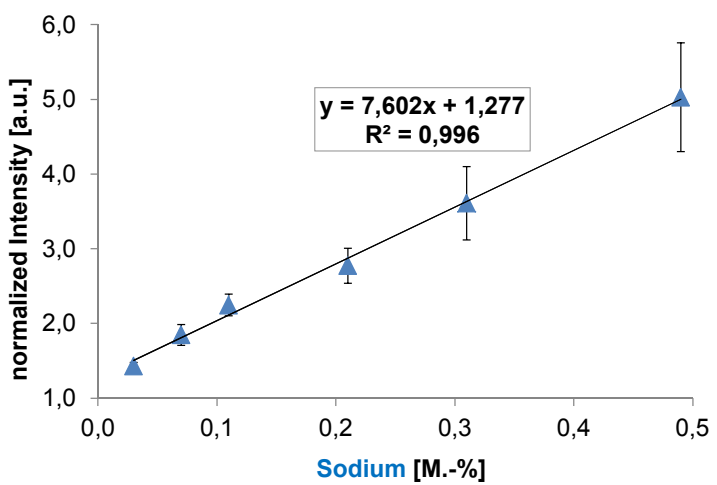

Fig. 7 Calibration line for sodium.

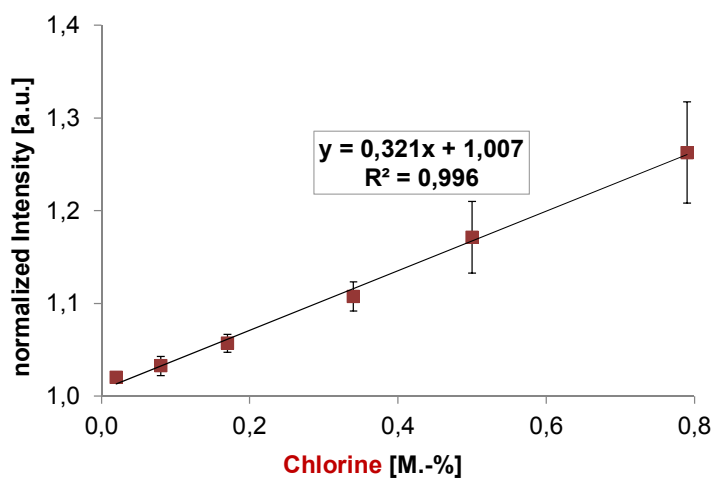

Fig. 8 Calibration line for chlorine.

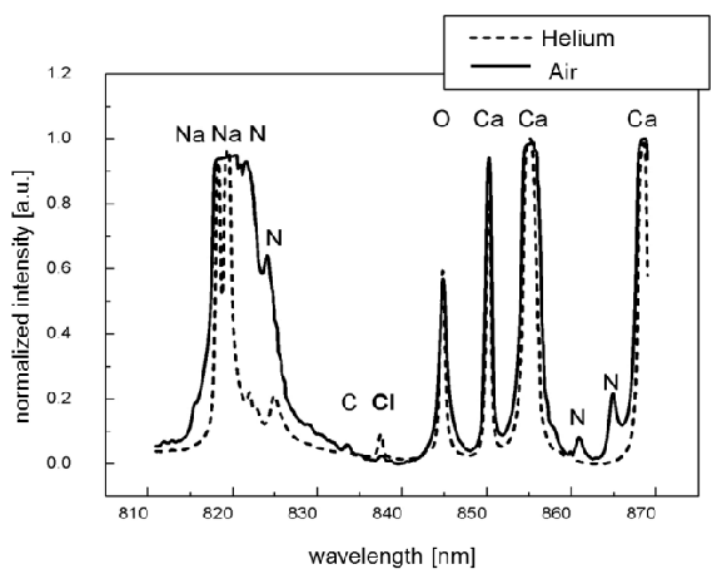

Fig. 9 Comparison of two spectra measured on the same sample. The bold line shows the measured intensities in air atmosphere. The dotted line represents the measurement in helium atmosphere.

As can be deduced from the data shown, the standard deviation of the mean values is $11 \%$.

In addition, LIBS enables significantly faster measurements. For example, for OPC samples, an area of $140 \mathrm{~mm} \times 140 \mathrm{~mm}$ was scanned in $90 \mathrm{~min}$, which is a lot faster compared to other techniques.

Thus, in comparison to EPMA, losses concerning the spot size and the spatial resolution are balanced by advantages of a fast and reliable measuring technique which does not need significant sample preparation and no vacuum condition. 


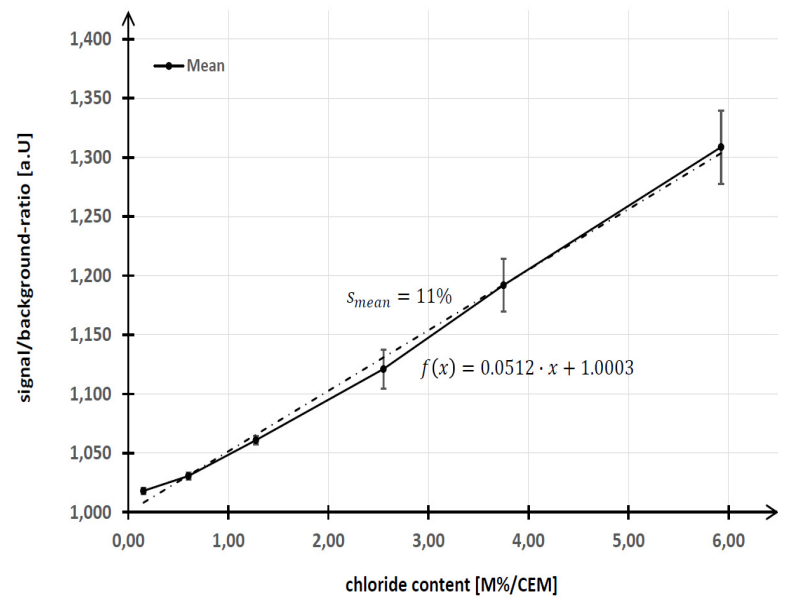

Fig. 10 Comparison of four calibration curves for chloride measured within one month.

\subsubsection{Current study}

Specimens from two tested series were exposed and prepared for LIBS analysis in TU Delft, as explained in chapter 2.2. Then, they were shipped to Berlin for LIBS analysis.

In the current study, the OPC series was scanned using a grid of $140 \times 140$ locations, and the slag series using a grid of $150 \times 110$ locations, both with a spacing of $1 \mathrm{~mm}$. After processing the results, two dimensional element distributions on the analysed surface are obtained.

After the LIBS analysis was performed at BAM in Berlin, the specimens were shipped back to Delft for examination of the cracks. They were impregnated under vacuum with fluorescent low viscosity epoxy, which enabled visual examination of cracks under UV light. After the impregnation, the exposed surface was polished to remove excess epoxy. Then, photos of the specimens were taken under UV light. These were processed and included in the results section, together with corresponding element profiles. Unfortunately, several specimens broke during shipping, so they were not impregnated and examined. For those specimens, no images of impregnated cracks are available.

\section{Results and discussion}

\subsection{Cracking}

In a MWST specimen, a vertical crack typically develops starting from the notch. As the crack widens, it reaches the reinforcing steel, branches horizontally, parallel to the reinforcement and around it. This behaviour was observed and studied non-destructively (using concrete resistance measurements) and destructively (using fluorescent epoxy impregnation) in a related study (Pacheco et al. 2014). This branching is similar to the behaviour of reinforced concrete beams subjected to bending loads, as shown by Pease (2010). In his study, the concrete cover was cut off in order to expose the steel rebar for visual monitoring. Then, photogrammetric assessment was used to study cracking behaviour in
Table 2 Crack widths.

\begin{tabular}{|c|c|c|}
\hline Specimen & $\begin{array}{c}\text { Loaded } \\
\text { crack width }(\mu \mathrm{m})\end{array}$ & $\begin{array}{c}\text { Unloaded } \\
\text { crack width }(\mu \mathrm{m})\end{array}$ \\
\hline OPC-55 & 100 & 55 \\
\hline OPC-80 & 151 & 80 \\
\hline OPC-115 & 203 & 115 \\
\hline OPC-165 & 249 & 165 \\
\hline OPC-186 & 299 & 186 \\
\hline OPC-190 & 300 & 190 \\
\hline OPC-217 & 292 & 217 \\
\hline OPC-305 & 400 & 305 \\
\hline Slag-55 & 96 & 55 \\
\hline Slag-162 & 289 & 162 \\
\hline Slag-212 & 386 & 212 \\
\hline Slag-313 & 482 & 313 \\
\hline Slag-424 & 579 & 424 \\
\hline
\end{tabular}

the steel/concrete interface of RC beams.

A typical vertical load-average COD curve is shown in Fig. 11. The first part of the curve includes elastic deformation and occurrence of nonlinearity close to the peak load. It is followed by a descending branch, as the stiffness of the specimen is reduced due to cracking. Once a target COD is achieved (denoted as Loaded crack width in Fig. 11), the specimen is unloaded, and the crack partially closes. The final crack width (denoted as Unloaded crack width in Fig. 11) is noted and used in further analyses. Crack widths of all analysed specimens are shown in Table 2. As will be further shown, this crack branching around the reinforcement is reflected in chloride and sodium distributions in exposed specimens.

\subsection{LIBS}

In Figs. 14-21, chloride and sodium profiles are shown for the OPC series specimens. In Figs. 22-26, chloride and sodium profiles are shown for the slag series specimens. The distribution of $\mathrm{Cl}$ and $\mathrm{Na}$ on the whole analysed surface of the specimen OPC-55 is shown in Fig. 14. Then, the aggregate particles are excluded, since they present impermeable inclusions and therefore obstacles to chloride penetration, and contain no chloride. However, some aggregate particles do contain iron, which can be an issue for chloride content evaluation,

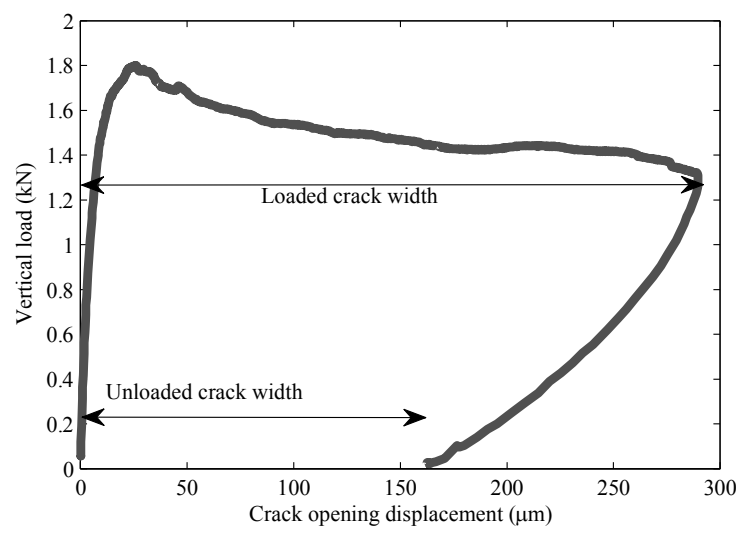

Fig. 11. A typical load-displacement curve for MWST. 
because iron peaks in aggregate particles are close to the chlorine peak in the matrix (Fig. 12). Aggregate particles are discriminated based on a $\mathrm{Ca}$ to $O$ ratio, because the aggregate particles contain no $\mathrm{Ca}$, while on the contrary cement paste contains plenty of $\mathrm{Ca}$. More details on how the aggregate particles are discerned can be found in Weritz et al. (2006). Results of all other specimens are displayed only for the case without coarse aggregates. In the slag series, also areas in the mortar matrix which are rich in iron are excluded. Similarly to the case of aggregates containing some iron, iron rich areas in the matrix could be misinterpreted as chloride rich areas in the images, and are therefore not taken into account.

As already mentioned, LIBS can monitor movement of multiple elements at the same time. Apart from chloride and sodium, also element distributions of carbon, calcium, and oxygen are determined. As these were not the focus of this study, only an example is shown in Fig. 13.

It is clear that the ingress profiles follow the cracks. Similar behaviour was observed by Michel et al. (2013) in their study. In cases where cracks develop horizontally (parallel to the reinforcement), the ingress profiles change accordingly. As a consequence, corrosion behaviour is somewhat different in these cases. Namely, for wider cracks where debonding at the steel/concrete interface occurred, corrosion pits were present along the rebar (and not in the middle of the rebar). For narrow cracks, where no debonding occurred, the pits did occur only in the middle of the rebar, i.e. where the vertical crack is (Pacheco, 2014).

Much more significant chloride penetration was observed in the OPC series. Apart from the longer expo-

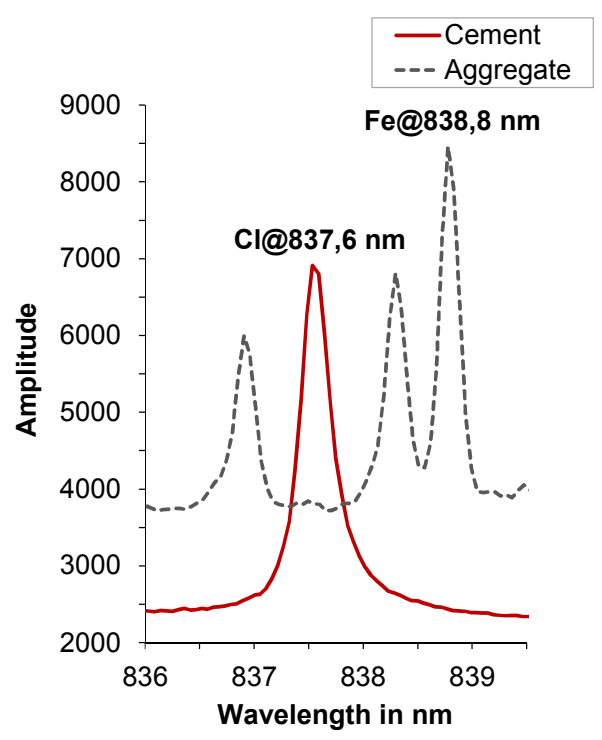

Fig. 12 Peak of $\mathrm{Fe}$ at $838.8 \mathrm{~nm}$ influence to peak of $\mathrm{Cl}$ at $837.6 \mathrm{~nm}$. The dotted line is a spectrum of an aggregate and the bold line a spectrum of the cement matrix with chlorine. The background increases in the presence of iron. The other lines in the dotted line are also Fe peaks. sure time for this series (45 vs. 36 weekly cycles for slag), there is also a significant difference in chloride diffusion coefficient between the two mixes. In a related study, the non-steady state migration coefficient of this OPC mix measured at 28 days according to the NT Build 492 (1999) was (9.76-12.80) x 10-12 $\mathrm{m}^{2} / \mathrm{s}$, while for the slag mix it is $(3.23-4.83) \times 10-12 \mathrm{~m}^{2} / \mathrm{s}$.

Typically, chloride ion distributions are obtained by wet chemical analysis of the concrete material. Grinding of consecutive layers (typically in the order of $1-5 \mathrm{~mm}$ each) provides powdered samples to be analysed. These samples give essentially averaged values of chloride content in a certain layer. While this provides relatively reliable data for one-dimensional chloride ingress (even though concrete is then treated as a homogeneous medium), it may not be sufficient for a case of cracked concrete. Even so, it is commonly used in the literature due to convenience and widespread availability. For example, Gowripalan et al. (2000) drilled holes around cracks using a dry 20-mm diameter rotary impact drill. Powdered samples from these cores were then analysed. In order to mimic and assess such approach here, two different subsets are analysed. First, a vertical subset (with a width of $20 \mathrm{~mm}$ ) is obtained by averaging out the chloride concentrations in the horizontal direction (Fig. 27a). This essentially means that, for each $\mathrm{mm}$, only a single value of chloride content is obtained based on an average chloride content over the width of the subset. Similarly, a horizontal subset is obtained for all analysed specimens (Fig. 27b). In this way, a onedimensional chloride profile is obtained, without taking into account the crack shape and the width of the contaminated zone around the crack.

It can be seen in Fig. 28a that, in OPC specimens with crack widths between $55 \mu \mathrm{m}$ and $165 \mu \mathrm{m}$, a very small increase in chloride content is observed in this way. It is somewhat higher in specimens with cracks wider than $186 \mu \mathrm{m}$. In all cases, the maximum values of chloride content seem to be relatively low (compared to Fig. 14-21) due to the "averaging".

A similar trend is observed for the vertical average in slag specimens (Fig. 28b). A minor increase in chloride content is observed in this way, except for the specimen with the widest crack $(424 \mu \mathrm{m})$, where it is somewhat higher. This way of testing would grossly underestimate maximum values of chloride content in such concrete (i.e. with low diffusivity) due to low penetration of chloride to the sides of the crack (see Figs. 22-26).

In Fig. 29a, the presence of a crack is notable in all OPC specimens when horizontal averaging (as shown in Fig. 27b) is performed. The trend clearly shows a peak in the middle of the profile which is higher the wider the crack is. However, similar to the vertical profiles, the averaging "smears" the chloride contents, so maximum values are lower than found in Figs. 14-21. Similar to the OPC series, a presence of a crack can be observed in horizontally averaged profiles in slag specimens (Fig. 29b). Also here, the peak in the middle of the profile is 


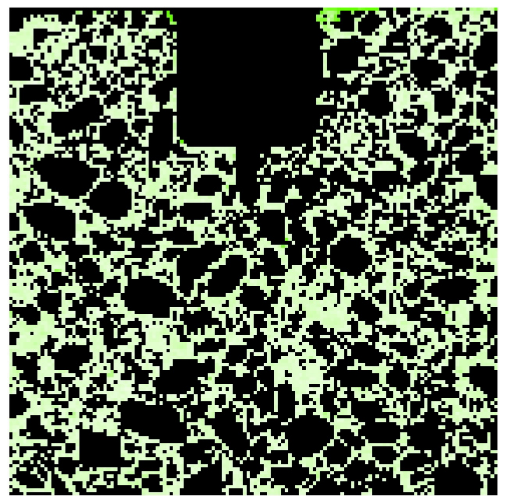

(a)

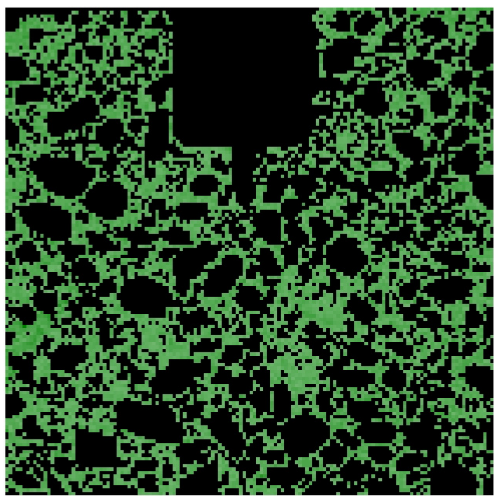

(b)

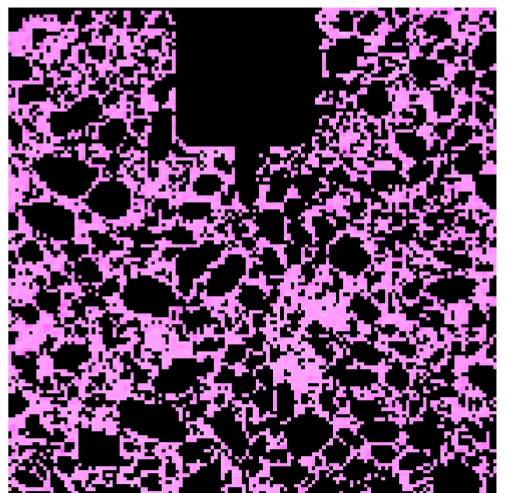

(c)

Fig. 13 Element maps of carbon (a), calcium (b), and oxygen (c) with aggregate particles excluded for OPC-55 specimen. The results are not quantitative. Note the increase in carbon content in the surface layer of the top surface, probably due to carbonation.

higher when the crack is wider. But, again, maximal values of the chloride content are underestimated (Figs. 22-26).

When comparing different experimental techniques for determining chloride distribution/profiles in concrete, it has to be noted that it is not the average chloride content at the level of the reinforcement that causes its depassivation (i.e. beginning of the corrosion process), but the maximum value (Yu and Hartt 2010). In a study by Angst and Polder (2014), a difference of $20-70 \%$ was found between a "microscopic" and "macroscopic" chloride content in a homogeneously exposed area, attributed solely to heterogeneity of concrete. In fact, it seems that the larger the aggregate particles in the concrete mix, the higher the deviation from the "ideal" (i.e. uniform) chloride profile (Yu and Hartt 2010). The deviation is even higher in the presence of cracks, as shown here. This implies that a "macroscopic" technique would underestimate the chloride content around the crack and at the level of the steel, in comparison with a meso-scale technique such as LIBS. A large scatter in experimental results would then be expected. It is therefore advised to use meso- or micro-scale techniques (e.g. LIBS, LA-ICP-MS (Silva et al. 2013), EPMA (Win et al. 2004; Mori et al. 2006) or EDS (Energy-dispersive X-ray spectrometry) (Pacheco et al. 2012) when dealing with problems that require high spatial resolution, such as chloride distribution in cracked concrete or critical chloride content analyses.

\section{Summary and conclusions}

In this paper, influence of cover cracking on chloride ingress into concrete under wet/dry cycles is investigated. First, a method for specimen preparation and cracking, which mimics the cracking behaviour of reinforced beam elements, is proposed. Secondly, specimens prepared with two concrete mixtures (using Portland cement and blast furnace slag cement) were exposed to wetting and drying cycles with $\mathrm{NaCl}$ solution for a prolonged time period. Afterwards, they were cut and chloride ingress examined. For chloride profiling, Laser Induced Breakdown Spectroscopy (LIBS), a meso-scale technique, was used. Based on this study, the following conclusions can be drawn:

- The proposed cracking method and specimen design enable creating bending type cracks, with debonding occurring at the steel/concrete interface. This is similar to the behaviour of reinforced concrete beams.

- LIBS can be used as a reliable tool for twodimensional elemental mapping on the meso-scale. Multiple elements can be measured in the same analysis, which is an advantage over wet chemical techniques. 


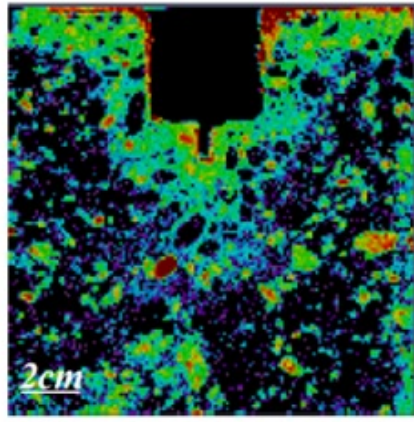

(a) $\mathrm{Cl}$ (aggregates included)

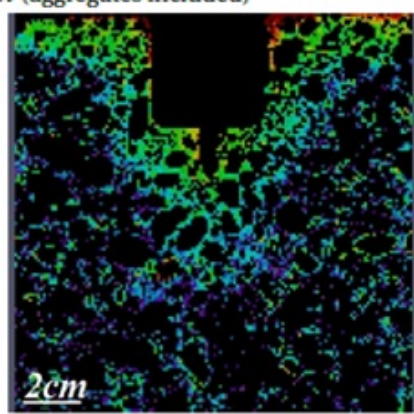

(c) $\mathrm{Cl}$ (aggregates excluded)

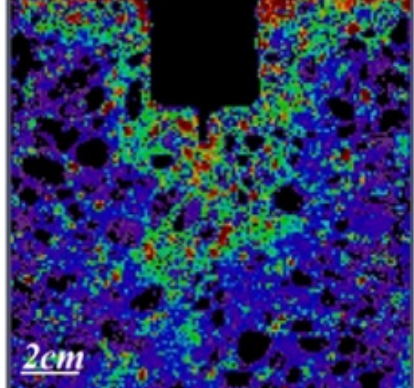

(b) $\mathrm{Na}$ (aggregates included)

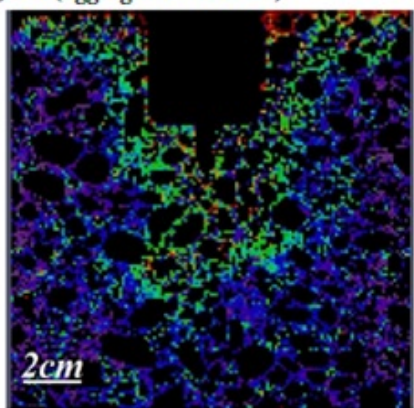

(d) $\mathrm{Na}$ (aggregates excluded)

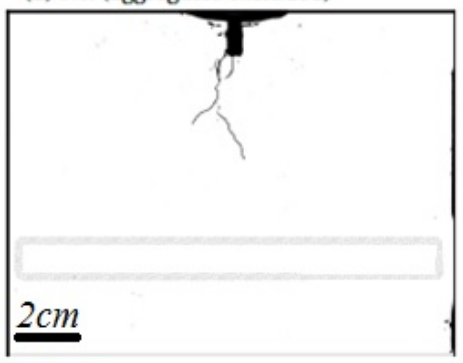

(f) Crack

Fig. 14 Chloride $(\mathrm{Cl})$ and sodium (Na) distributions determined by LIBS analysis (a-d); legend (e); crack and vertical rebar position ( $f$ ) in OPC-55 specimen.

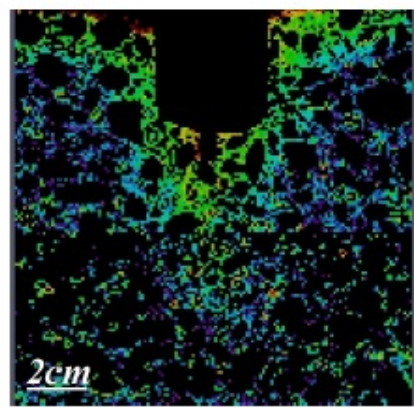

(a) $\mathrm{Cl}$ (aggregates excluded)

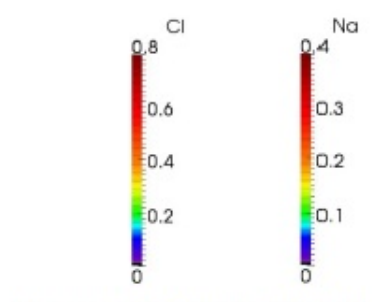

(c) Legend for element distributions (in \% of mortar weight

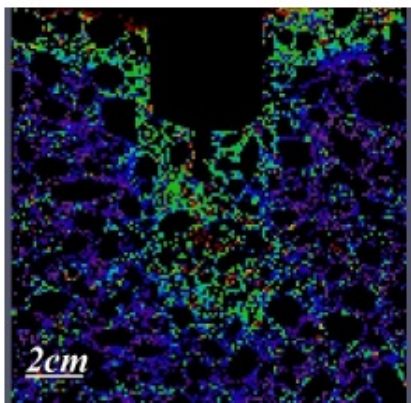

(b) $\mathrm{Na}$ (aggregates excluded)

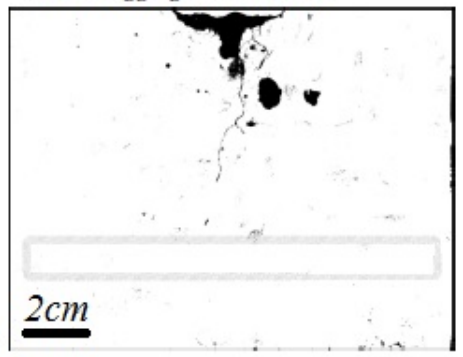

(d) Crack

Fig. 15 Chloride $(\mathrm{Cl})$ and sodium $(\mathrm{Na})$ distributions determined by LIBS analysis (a,b); legend (c); crack and vertical rebar position (d) in OPC-80 specimen. 


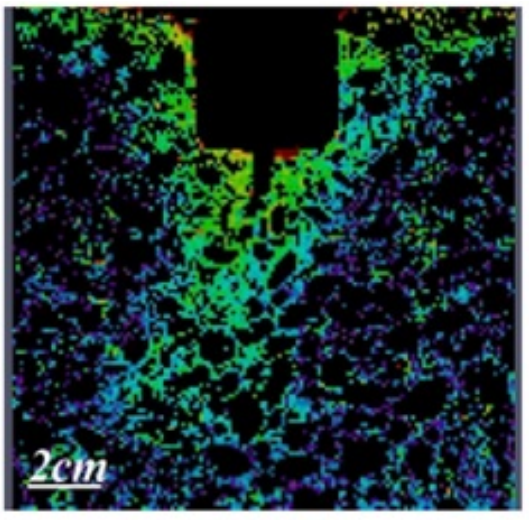

(a) $\mathrm{Cl}$ (aggregates excluded)

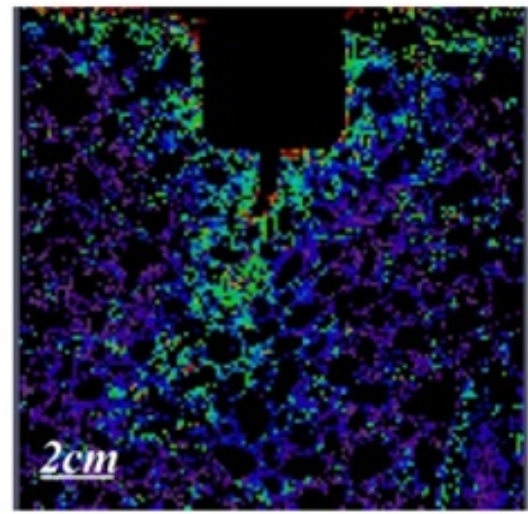

(b) $\mathrm{Na}$ (aggregates excluded)

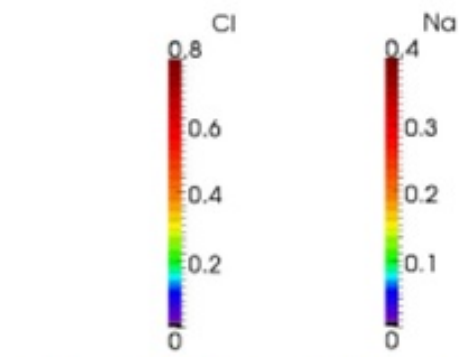

(c) Legend for element distributions (in \% of mortar weight)

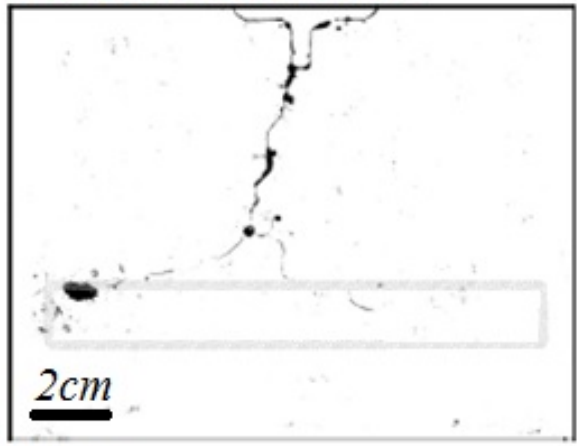

(d) Crack

Fig. 16 Chloride $(\mathrm{Cl})$ and sodium $(\mathrm{Na})$ distributions determined by LIBS analysis (a,b); legend (c); crack and vertical rebar position (d) in OPC-115 specimen.

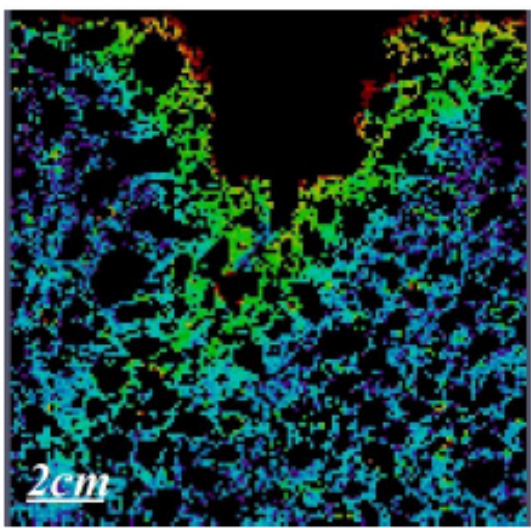

(a) $\mathrm{Cl}$ (aggregates excluded)

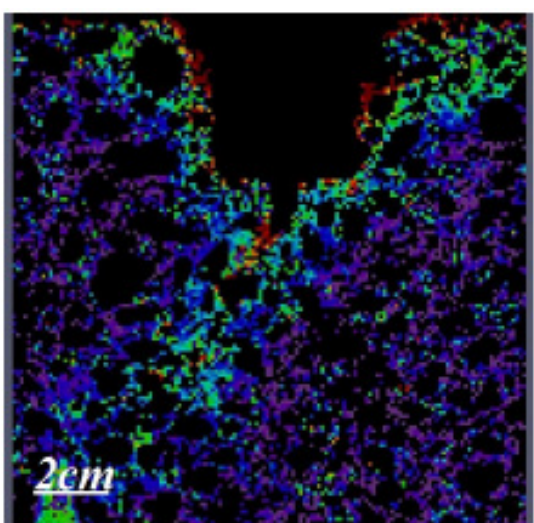

(b) $\mathrm{Na}$ (aggregates excluded)

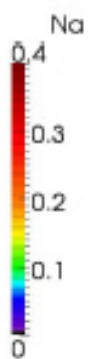

(c) Legend for element distributions (in \% of mortar weight)

Fig. 17 Chloride $(\mathrm{Cl})$ and sodium $(\mathrm{Na})$ distributions determined by LIBS analysis (a,b); and legend (c) in OPC-165 specimen. Note that this specimen broke during shipping and was therefore not impregnated, so an image of the cracks is not available. 


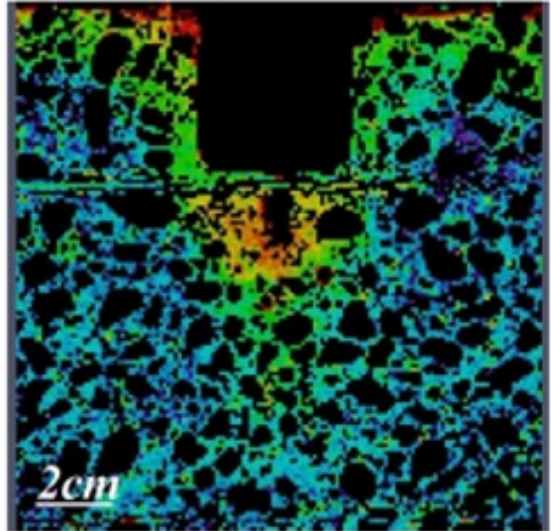

(a) $\mathrm{Cl}$ (aggregates excluded)

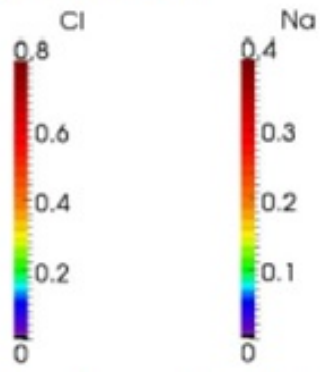

(c) Legend for element distributions (in \% of mortar weight)

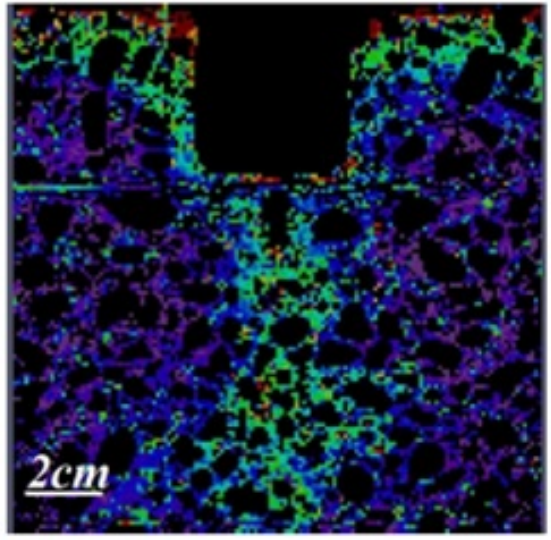

(b) $\mathrm{Na}$ (aggregates excluded)

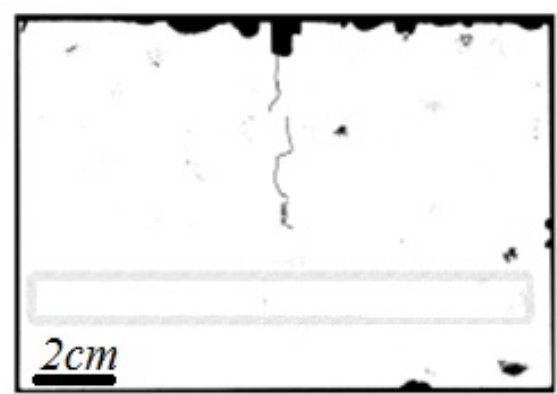

(d) Crack

Fig. 18 Chloride $(\mathrm{Cl})$ and sodium $(\mathrm{Na})$ distributions determined by LIBS analysis (a,b); legend (c); crack and vertical rebar position (d) in OPC-186 specimen.

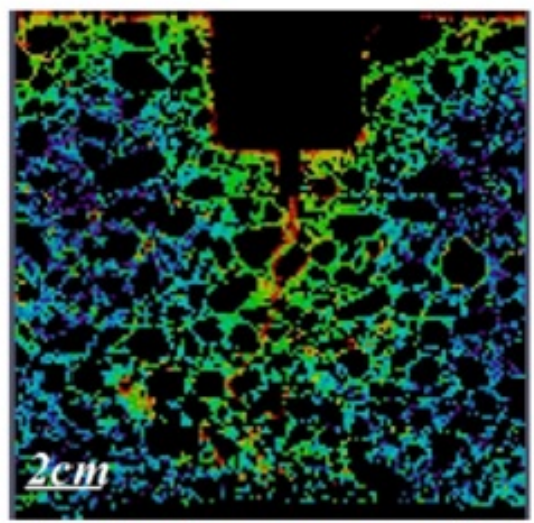

(a) $\mathrm{Cl}$ (aggregates excluded)

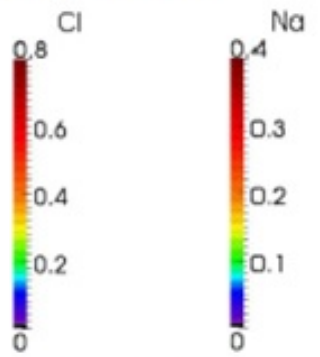

(c) Legend for element distributions (in \% of mortar weight)

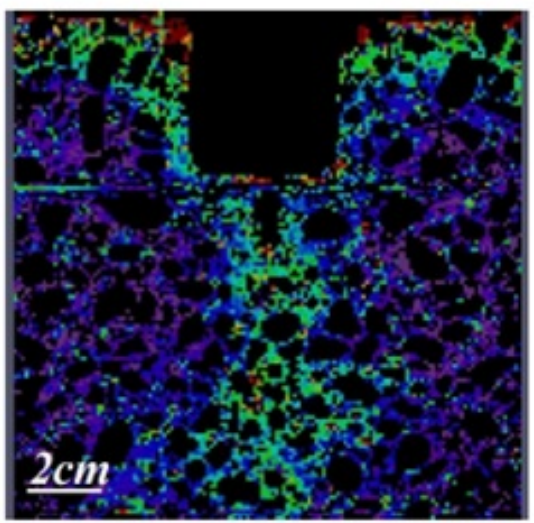

(b) $\mathrm{Na}$ (aggregates excluded)

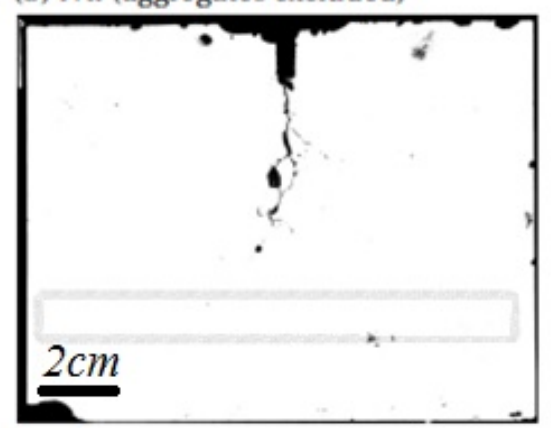

(d) Crack

Fig. 19 Chloride $(\mathrm{Cl})$ and sodium $(\mathrm{Na})$ distributions determined by LIBS analysis (a,b); legend (c); crack and vertical rebar position (d) in OPC-190 specimen. 


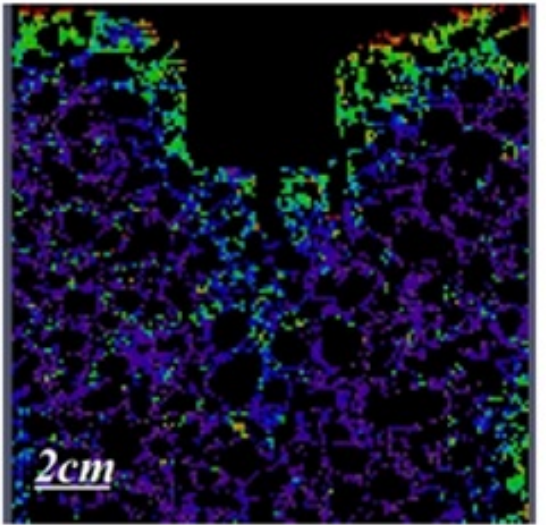

(a) $\mathrm{Cl}$ (aggregates excluded)

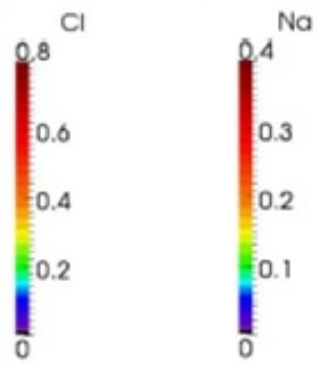

(c) Legend for element distributions (in \% of mortar weight)

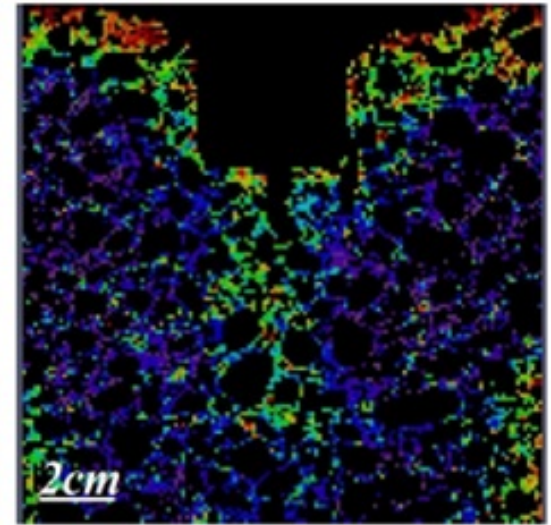

(b) $\mathrm{Na}$ (aggregates excluded)

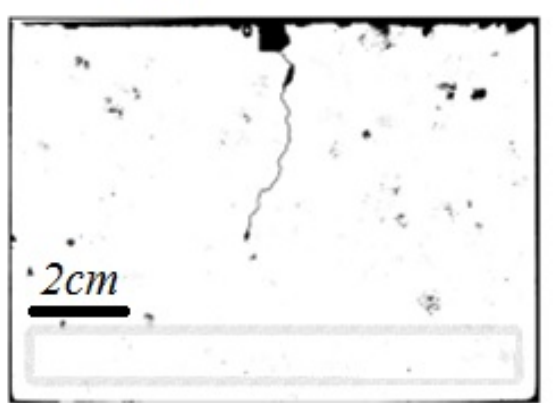

(d) Crack

Fig. 20 Chloride $(\mathrm{Cl})$ and sodium ( $\mathrm{Na}$ ) distributions determined by LIBS analysis (a,b); legend (c); crack and vertical rebar position (d) in OPC-217 specimen.

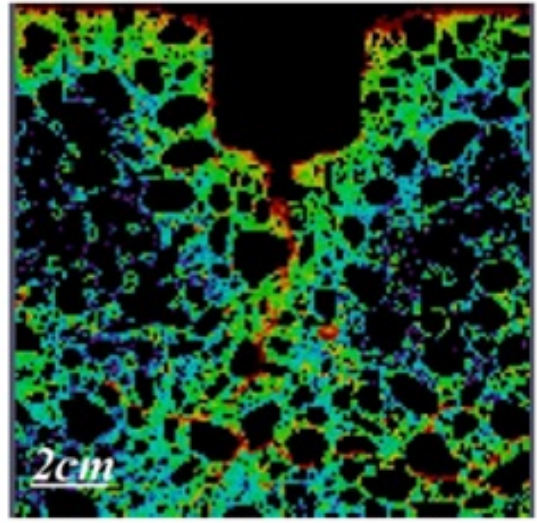

(a) $\mathrm{Cl}$ (aggregates excluded)

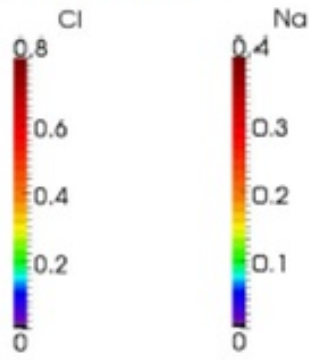

(c) Legend for element distributions (in \% of mortar weight)

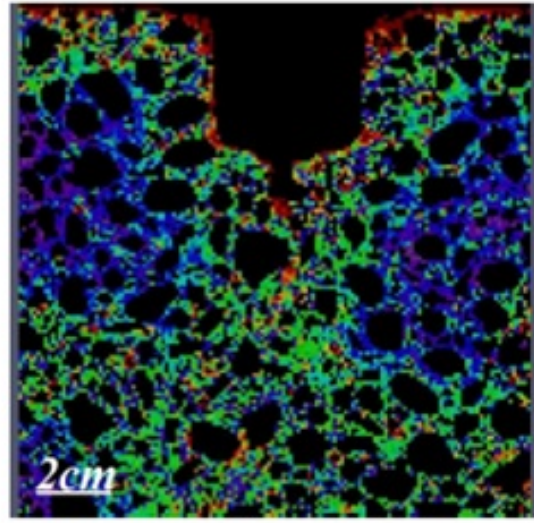

(b) $\mathrm{Na}$ (aggregates excluded)

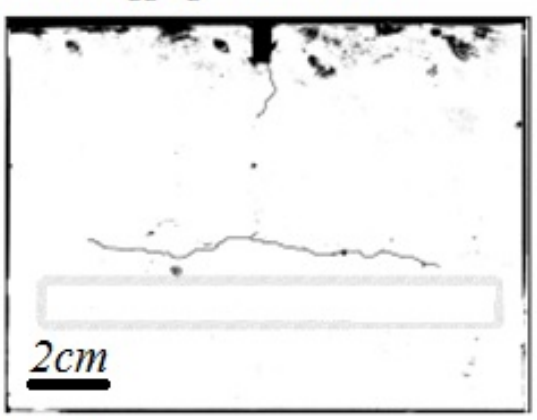

(d) Crack

Fig. 21 Chloride $(\mathrm{Cl})$ and sodium ( $\mathrm{Na}$ ) distributions determined by LIBS analysis (a,b); legend (c); crack and vertical rebar position (d) in OPC-305 specimen. 

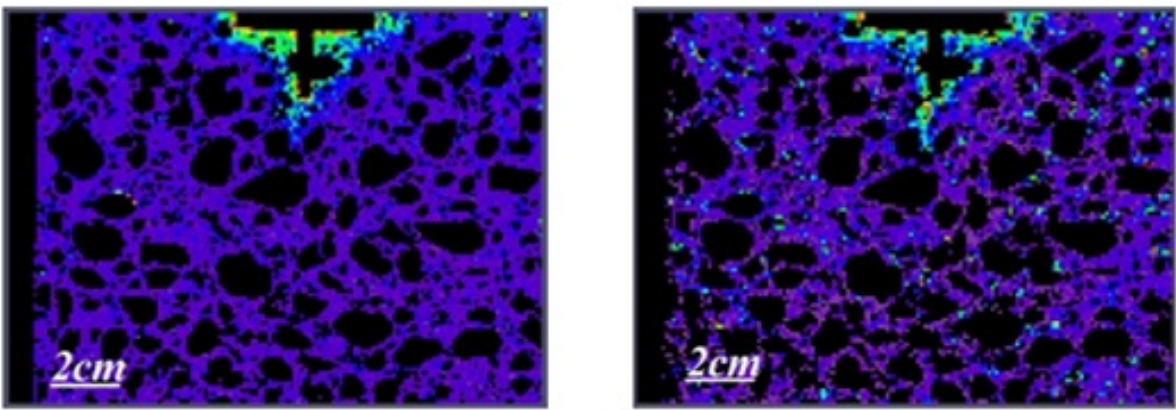

(a) $\mathrm{Cl}$ (aggregates and $\mathrm{Fe}$ rich areas ex- (b) $\mathrm{Na}$ (aggregates and $\mathrm{Fe}$ rich areas excluded) cluded)

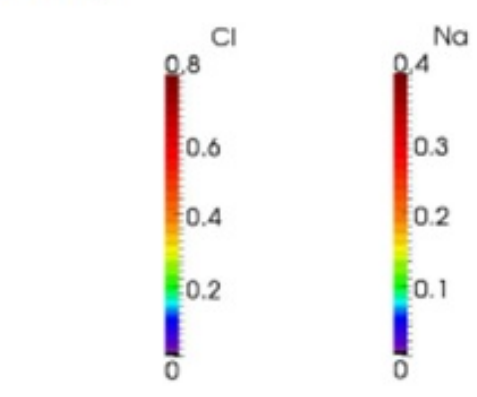

(c) Legend for element distributions (in \% of

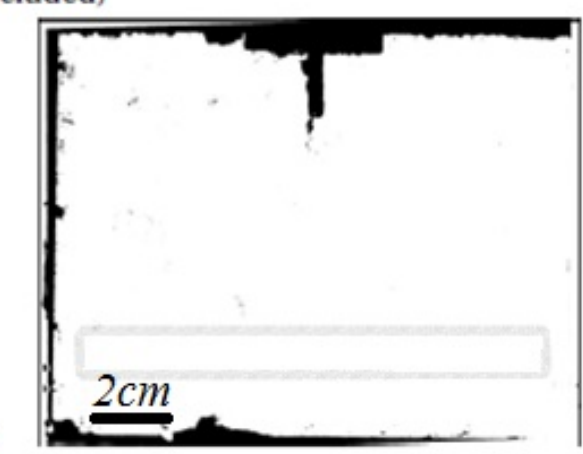
mortar weight)

(d) Crack

Fig. 22 Chloride $(\mathrm{Cl})$ and sodium ( $\mathrm{Na}$ ) distributions determined by LIBS analysis (a,b); legend (c); crack and vertical rebar position (d) in Slag-55 specimen.
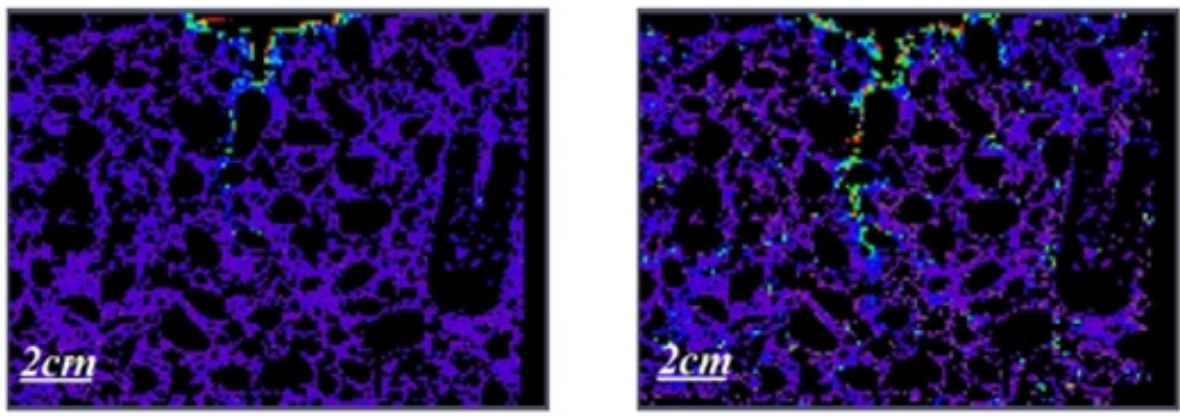

(a) $\mathrm{Cl}$ (aggregates and $\mathrm{Fe}$ rich areas ex-(b) $\mathrm{Na}$ (aggregates and $\mathrm{Fe}$ rich areas excluded) cluded)

(c) Legend for element distributions (in \% of
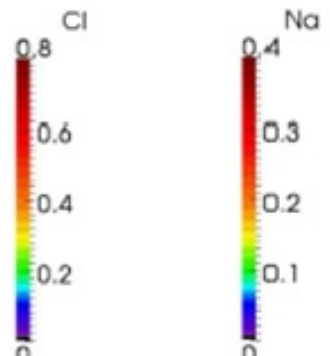
mortar weight)

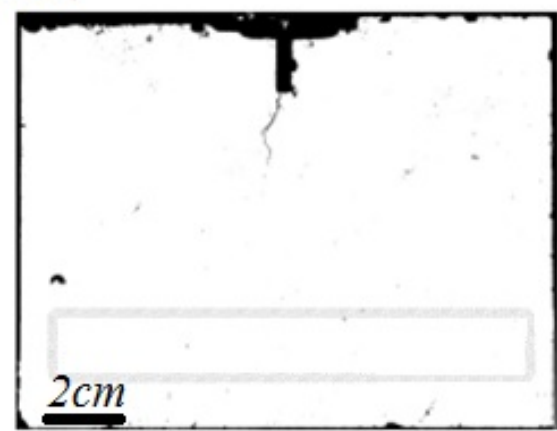

(d) Crack

Fig. 23 Chloride $(\mathrm{Cl})$ and sodium ( $\mathrm{Na}$ ) distributions determined by LIBS analysis (a,b); legend (c); crack and vertical rebar position (d) in Slag-162 specimen. 


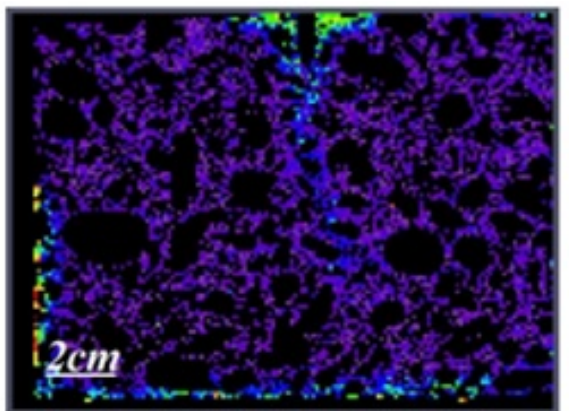

(a) $\mathrm{Cl}$ (aggregates and $\mathrm{Fe}$ rich areas ex-(b) $\mathrm{Na}$ (aggregates and $\mathrm{Fe}$ rich areas excluded)
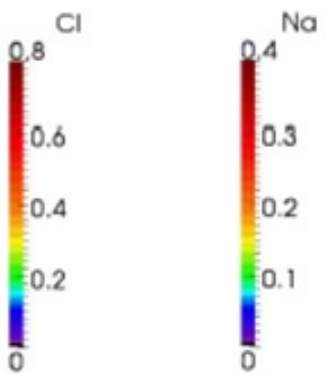

(c) Legend for element distributions (in \% of mortar weight)

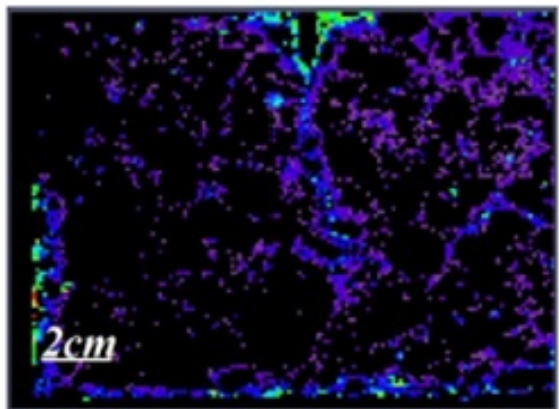

cluded)

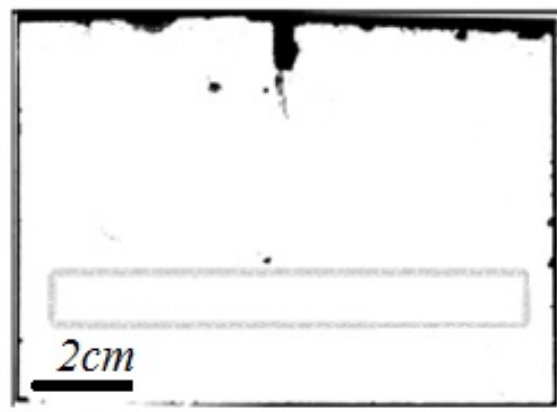

(d) Crack

Fig. 24 Chloride $(\mathrm{Cl})$ and sodium ( $\mathrm{Na}$ ) distributions determined by LIBS analysis (a,b); legend (c); crack and vertical rebar position (d) in Slag-212 specimen.

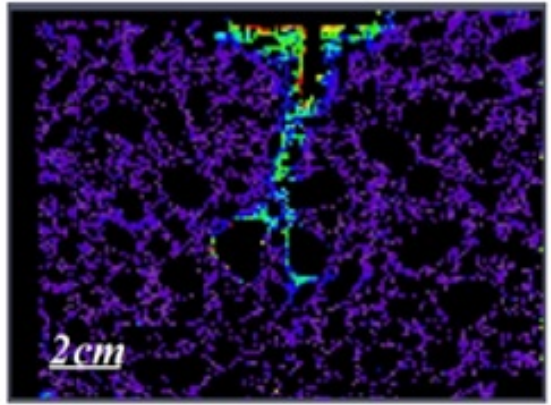

(a) $\mathrm{Cl}$ (aggregates and $\mathrm{Fe}$ rich areas ex- (b) $\mathrm{Na}$ (aggregates and $\mathrm{Fe}$ rich areas excluded)

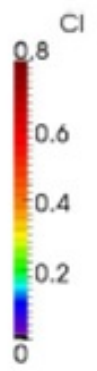

(c) Legend for element distributions (in \% of

mortar weight)

(d) Crack

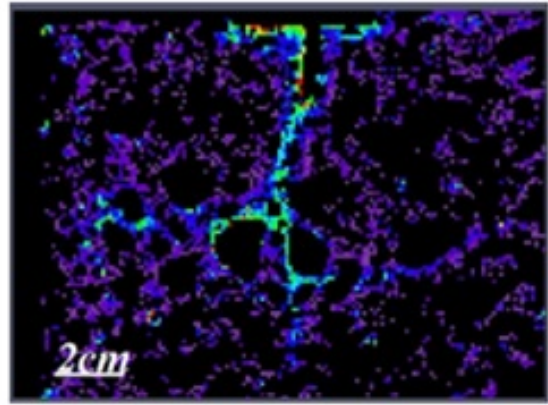

cluded)

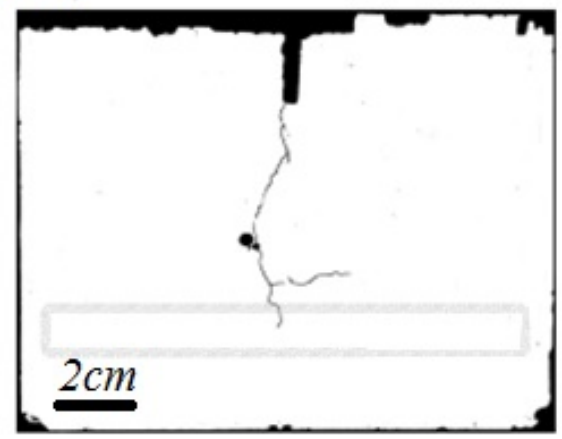

Fig. 25 Chloride $(\mathrm{Cl})$ and sodium ( $\mathrm{Na}$ ) distributions determined by LIBS analysis (a,b); legend (c); crack and vertical rebar position (d) in Slag-313 specimen. 

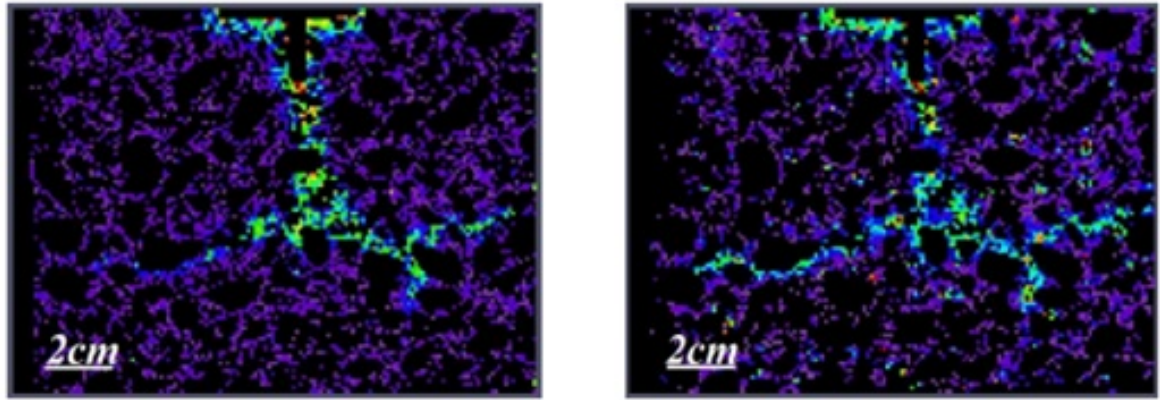

(a) $\mathrm{Cl}$ (aggregates and $\mathrm{Fe}$ rich areas ex- (b) $\mathrm{Na}$ (aggregates and $\mathrm{Fe}$ rich areas excluded) cluded)

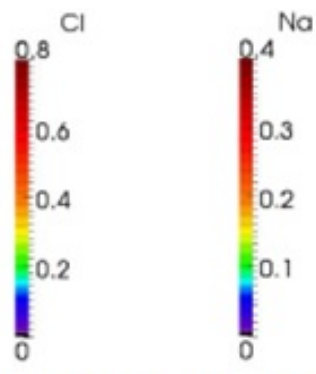

(c) Legend for element distributions (in \% of mortar weight)

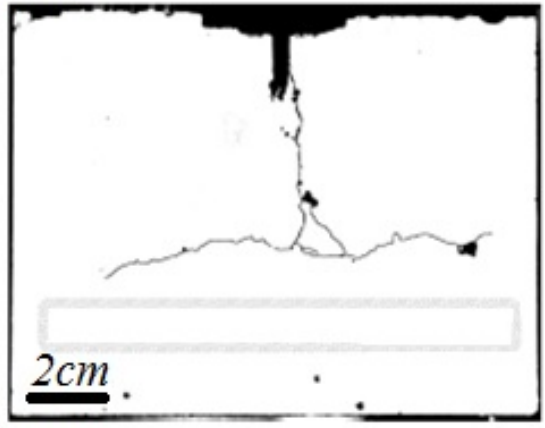

(d) Crack

Fig. 26 Chloride $(\mathrm{Cl})$ and sodium ( $\mathrm{Na}$ ) distributions determined by LIBS analysis (a,b); legend (c); crack and vertical rebar position (d) in Slag-424 specimen.

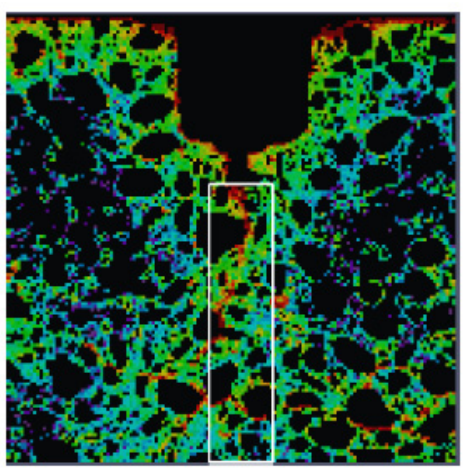

(a) Vertical subset

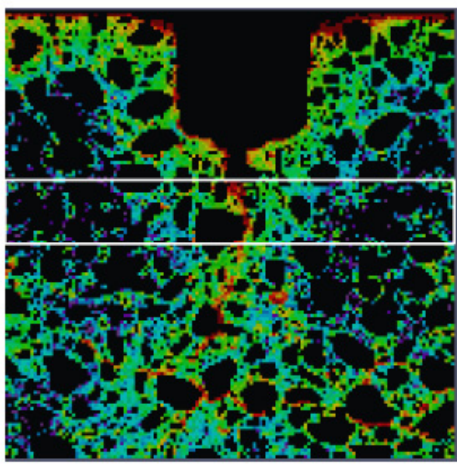

(b) Horizontal subset

Fig. 27 Definition of subsets for averaging of chloride content. 


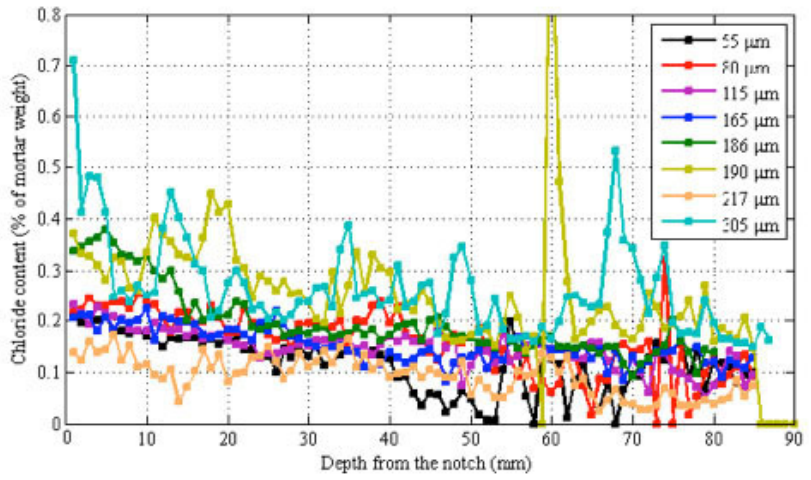

(a) OPC

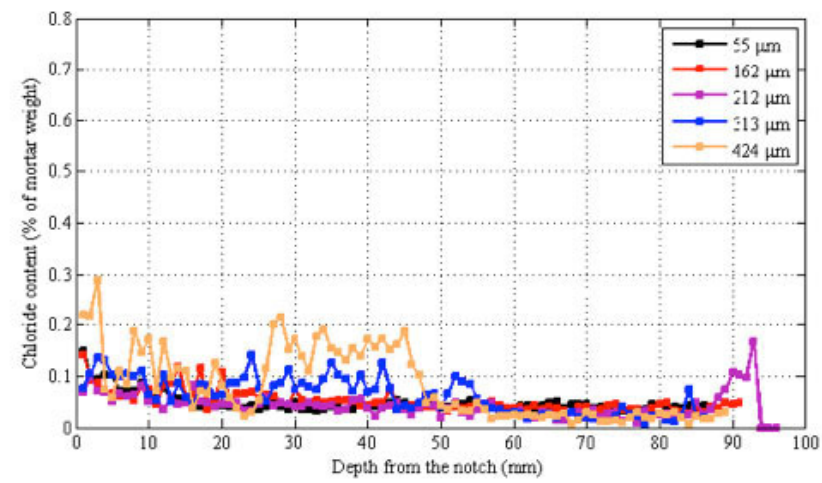

(b) Slag

Fig. 28 Vertical averaged chloride contents over the subset width.

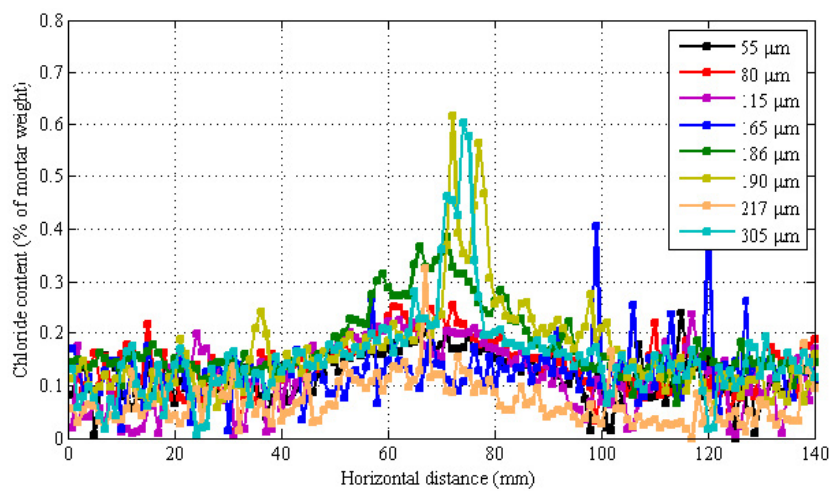

(a) OPC

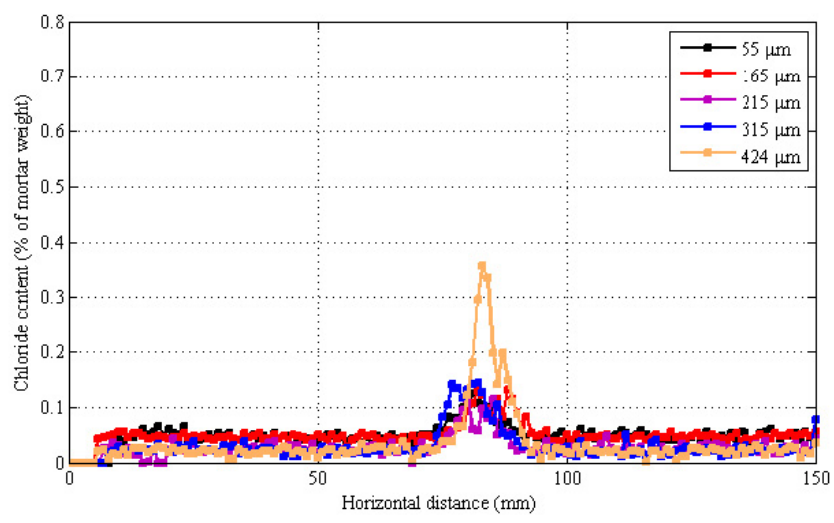

(b) Slag

Fig. 29 Horizontal averaged chloride contents over the subset width. 
- Chloride ingress is affected by the cracking. The wider the surface crack, the more chloride penetration occurs. In wide cracks, penetration of chloride ions parallel to the steel occurs, due to the damage in the steel/concrete interface.

- Chloride penetration depth, both at the exposed surface and around the cracks, is much higher in OPC than in slag specimens. This is also true for cracks which propagate around the steel/concrete interface.

- Macro-scale techniques for chloride profiling (such as powder grinding and wet chemical analysis) may underestimate chloride contents around cracks, especially in concrete with low diffusion coefficients. Therefore, use of meso- or micro-scale techniques (such as LIBS herein) is advised when high spatial resolution of element distributions is sought.

When studying chloride ingress in cracked concrete, it is important to use reinforced specimens, since their cracking behaviour is different than plain concrete. This is important, as chloride ingress is not an issue in plain concrete. From this paper, it is clear that cracking has a marked influence on chloride ingress, and therefore on the initiation period of reinforcement corrosion. However, the impact of chloride ingress on long-term durability of cracked concrete cannot be assessed by only studying chloride ingress. It is important to monitor the behaviour of reinforcement steel, which is part of a related study (Pacheco 2014). Finally, the impact of cracking on short- and long-term durability (i.e. the initiation and the propagation period of reinforcement corrosion, as defined by Tutti (1982)) can be found only through synergy of these approaches.

\section{Acknowledgements}

The authors would like to thank Ger Nagtegaal for his assistance in specimen fabrication and cracking. Financial support by the Dutch Technology Foundation (STW) for the project 10978-"Measuring, Modelling, and Monitoring Chloride ingress and Corrosion initiation in Cracked Concrete (M3C4)" is gratefully acknowledged.

\section{References}

Angst, U.M. \& Polder, R.B., (2014). “ Spatial variability of chloride in concrete within homogeneously exposed areas." Cement and Concrete Research, 56, 40-51.

Arya, C. \& Ofori-Darko, F., (1996). "Influence of crack frequency on reinforcement corrosion in concrete." Cement and Concrete Research, 26, 345-353.

Brühwiler, E. \& Wittmann, F. H., (1990). "The wedge splitting test, a new method of performing stable fracture mechanics tests." Engineering Fracture Mechanics, 35(1/2/3), 117-125.

François, R., Khan, I., Mercado, H., and Castel, A., (2011). "Influence of mechanical cracks on the development of corrosion mechanism." In: C. K. Y. Leung and K. T. Wan Eds. International Conference on Advances in Construction Materials through Science and Engineering, Hong Kong.

Gehlen, C. D., Wiens, E., Noll, R., Wilsch, G. and Reichling, K., (2009). "Chlorine detection in cement with laser-induced breakdown spectroscopy in the infrared and ultraviolet spectral range." Spectrochimica Acta B: Atomic Spectroscopy, 46, 1135-1140.

Gondal, M., Dastageer, A., Maslehuddin, M., Alnehmi, A. and Al-Amoudi, O., (2011). "Sensitivity enhancement at $594.8 \mathrm{~nm}$ atomic transition of $\mathrm{Cl} \mathrm{I}$ for chloride detection in the reinforced concrete using LIBS." Journal of Environmental Science and Health, Part A: Toxic/Hazardous Substances and Environmental Engineering, 46, 198-203.

Goto, Y., (1971). "Cracks formed in concrete around deformed tension bars." ACI Journal Proceedings, 68(4), 244-251.

Gowripalan, N., Sirivivatnanon, V., \& Lim, C. C., (2000). "Chloride diffusivity of concrete cracked in flexure." Cement and Concrete Research, 30(5), 725730.

Michel, A., Solgaard, A. O. S., Pease, B. J., Geiker, M. R., Stang, H. and Olesen, J. F., (2013). "Experimental investigation of the relation between damage at the concrete-steel interface and initiation of reinforcement corrosion in plain and fibre reinforced concrete." Corrosion Science, 77, 308-321.

Mori, D., Yamada, K., Hosokawa, Y., and Yamamoto, M. (2006). "Applications of electron probe microanalyzer for measurement of $\mathrm{Cl}$ concentration profile in concrete". Journal of Advanced Concrete Technology, 4(3), 369-383.

NT BUILD 492, (1999), "Concrete, mortar, and cement-based repair materials: chloride migration coefficient from non-steady state migration experiments." Nordtest, Espoo, Finland

Pacheco, J. and Polder, R. B., (2012). "Corrosion initiation and propagation in cracked concrete - a literature review." In: C. Andrade and J. Gulikers Eds. Advances in modelling concrete service life, Springer, 85-93.

Pacheco, J., Çopuroğlu, O., Šavija, B., Schlangen, E., Polder, R. B., (2012). "Assessment of critical chloride content in reinforced concrete by Energy Dispersive Spectrometry (EDS)." In: M.G. Alexander, H.-D. Beushausen, F. Dehn and P. Moyo Eds. Concrete Repair, Rehabilitation and Retrofitting III, Proc. 3rd Int. Conf. on Concrete Repair, Rehabilitation and Retrofitting, Taylor \& Francis, Cape Town, South Africa, 511-516

Pacheco, J., Šavija, B., Schlangen, E., \& Polder, R. B., (2014). "Assessment of cracks in reinforced concrete by means of electrical resistance and image analysis." Construction and Building Materials, 65, 417-426.

Pacheco, J. (in preparation), "Corrosion of steel in cracked concrete." Thesis (PhD). Delft University of Technology. 
Pease, B. J., Couch, J., Geiker, M. R., Stang, H. and Weiss W. J., (2009). "Assessing the portion of the crack length contributing to water sorption using $\mathrm{X}$ ray absorption measurements on concrete wedge splitting specimens." ConcreteLife'09: Second International RILEM Workshop on Concrete Durability and Service Life Planning, Haifa, Israel.

Pease, B. J., (2010). "Influence of concrete cracking on ingress and reinforcement corrosion." Ph.D. thesis, Technical University of Denmark.

Reinhardt, H. W., Sosoro, M., and Zhu, X. F., (1998). "Cracked and repaired concrete subject to fluid penetration." Materials and Structures, 31(2), 74-83.

Silva, N., Luping, T. and Rauch, S., (2013). "Application of LA-ICP-MS for meso-scale chloride profiling in concrete." Materials and structures, 46(8), 1369-1381.

Sugiyama, K., Fujii, T., Matsumura, T., Shiogama, Y., Yamaguchi, M., \& Nemoto, K., (2010). "Detection of chlorine with concentration of $0.18 \mathrm{~kg} / \mathrm{m}^{3}$ in concrete by laser-induced breakdown spectroscopy." Applied Optics, 49(13), C181-C190.

Šavija, B., and Schlangen, E., (2012). "Chloride ingress in cracked concrete - a literature review." In: C. Andrade and J. Gulikers, Eds. Advances in modelling concrete service life. Springer,133-142.

Šavija, B., (2014). "Experimental and numerical investigation of chloride ingress in cracked concrete." Thesis (PhD). Delft University of Technology. DOI:http://dx.doi.org/10.4233/uuid:79915ffe-d062431f-a0ff-bc7628e802be

Tutti, K. (1982). "Corrosion of steel in concrete." Swedish Cement and Concrete Institute. No. 4. CIB,
Research Report

Weritz, F., Schaurich, D., Taffe, A. and Wilsch, G., (2006). "Effect of heterogeneity on the quantitative determination of trace elements in concrete." Analytical and Bioanalytical Chemistry, 385(2), 248255.

Wilsch, G., Weritz, F., Schaurich, D. and Wiggenhauser, H., (2005). "Determination of chloride content in concrete structures with laser-induced breakdown spectroscopy." Construction and building materials, 19(10), 724-730.

Wilsch, G., Schaurich, D. and Wiggenhauser, H., (2011). "Imaging laser analysis of building materials practical examples." In: Review of progress in quantitative non-destructive evaluation Volume 30A; Volume $30 B \quad 1335(1)$, 1315-1322. DOI: http://dx.doi.org/10.1063/1.3592085

Win, P. P., Watanabe, M. and Machida, A., (2004). "Penetration profile of chloride ion in cracked reinforced concrete." Cement and concrete research, 34(7), 1073-1079.

Yoon, I. S., Schlangen, E., Rooij, M. R. D. and Van Breugel, K., (2007). "The effect of cracks on chloride penetration into concrete." Key Engineering Materials, 348, 769-772.

Yu, H. and Hartt, W. H., (2010). "Modeling corrosion initiation of reinforcing steel in concrete: effect of non-diffusive coarse aggregate." Journal of composite materials, 45(2), 153-69.

Zhang, P., Wittmann, F. H., Zhao, T. and Lehmann, E. H., (2010). "Neutron imaging of water penetration into cracked steel reinforced concrete." Physica B: Condensed Matter, 405(7), 1866-1871. 